\title{
Evaluation of climate change effects in a coastal aquifer in Morocco using a density-dependent numerical model
}

\author{
Júlio Ferreira Carneiro • Mimoun Boughriba • \\ António Correia $\cdot$ Yassine Zarhloule • \\ Abdelkrim Rimi · Boubker El Houadi
}

Received: 16 February 2009/Accepted: 20 October 2009/Published online: 18 November 2009

(c) Springer-Verlag 2009

\begin{abstract}
A density-dependent numerical groundwater model was applied to study the climate change impact in a shallow aquifer in the Mediterranean coast of Morocco, the Saïdia aquifer. The stresses imposed to the model were derived from the IPCC emission scenarios and included recharge variation and sea level rise. The main effect of the climate change in the Saïdia aquifer will be a decrease in renewable resources, which in the worst-case scenario may decrease to $50-60 \%$ of present-day values, due to the decline in recharge and to a reduced inflow from the adjacent Triffa aquifer. The water quality will be affected mostly in the area immediately adjacent to the seashore, where salinity may increase up to $30 \mathrm{~g} / \mathrm{l}$. Localised areas may see a decrease in salinity due to the induced freshwater recharge from Oued Moulouya River and diminished inflow from high-salinity springs.
\end{abstract}

Keywords Coastal aquifer - Numerical modelling Climate change $\cdot$ Seawater intrusion - IPCC scenarios

J. F. Carneiro $(\bowtie) \cdot$ A. Correia

Geophysical Centre of Évora,

University of Évora, Évora, Portugal

e-mail: jcarneiro@uevora.pt

M. Boughriba · Y. Zarhloule

Laboratory of Hydrogeology-Environment, Faculty of Sciences, Oujda, Morocco

A. Rimi

Department of Earth Sciences, Scientific Institute,

Rabat, Morocco

B. El Houadi

Hydraulic Basin Agency of the Moulouya, Oujda, Morocco

\section{Introduction}

The fourth assessment report of the IPCC (2007) reinforces that consistent climate changes are underway and that the anticipated sea level rise, temperature increase and precipitation changes will affect freshwater resources, both in terms of quantity and quality (Bates et al. 2008). The extent to which the available water resources will be affected depends on the development pattern that will be pursued during the twenty-first century. The IPCC has put forward several development scenarios that result in different climate change impacts to water resources, but in any case it is likely that coastal aquifers in arid and semi-arid regions will suffer negative impacts from climate change, notably due to changes in the recharge pattern and to encroachment due to the rising seawater level (Danielopol et al. 2003; Holman 2006).

The IPCC reference scenario indicates that by 2099 the estimated global sea level rise can reach up to $48 \mathrm{~cm}$, with an average temperature increase in the west Mediterranean of $2.8^{\circ} \mathrm{C}$ and a mean precipitation decrease of around $12 \%$ (IPCC 2007). Because Mediterranean countries often rely on the exploitation of coastal aquifers for local or regional freshwater supply, climate change may have serious implication on the water supply systems (Moustadraf et al. 2008; Sherif and Singh 1999). Furthermore, coastal areas in North African countries, such as Morocco, are developing at a fast rate, due to demographic pressure and tourism, making these coastal areas quite vulnerable to climate change (Ben Kabbour et al. 2005; Cudennec et al. 2007). Therefore, it is of relevance to study the climate change impacts to the groundwater quality and quantity in coastal aquifers.

This paper addresses one such study, focusing on a shallow unconfined aquifer, the Saïdia coastal aquifer, 
located in the Mediterranean coast of Morocco. The climate change impacts are addressed with a numerical groundwater flow and transport model and using, as a basis, the IPCC climate change scenarios. The numerical model is used to simulate the influence of sea level rise and changes in recharge to the quantity and quality of groundwater, up to 2099. The purpose of the numerical model is not to forecast in a precise manner the behaviour of the aquifer in such long-term simulations, but rather the model is used to find the main trends in groundwater level and salinity changes. It is hoped that the conclusions of the simulations in such a small and simple water table aquifer as the one at Saïdia, may be of interest in addressing the climate change impact in larger, more complex aquifers.

"Overview of the study area" addresses the geologic and hydrogeological features of the aquifer, while the sections that follow are "Numerical model", "Stresses related to IPCC scenarios", "Results of the simulations", respectively. The main conclusions are listed in "Conclusions".

\section{Overview of the study area}

The plain of Saidia (Fig. 1) is located in northeast Morocco, at the coastal Mediterranean area often referred to as the Alboran Sea. The aquifer covers an area of around $30 \mathrm{~km}^{2}$, extending for $12 \mathrm{~km}$ in length by $2-3 \mathrm{~km}$ in width. The aquifer is limited to the west by Oued Moulouya River and to the south and southeast by a large cliff that truncates the hills of Oulad Mansour, which marks the limit of the coastal plain.
The aquifer is of local relevance, being used for irrigation purposes, since its high-salinity content does not allow other uses. The main exploitation areas are located in the fertile areas close to Oueds Kiss and Moulouya. The whole area is undergoing fast touristic development, with a large touristic resort being built by the seashore.

\section{Hydraulic features and flow conditions}

The aquifer is made up of a sequence of alluvial and beach deposits, mainly composed of fine to medium sands with remains of shells. The thickness of the aquifer varies from 10 to $25 \mathrm{~m}$, with maxima at two dunes that align parallel to the seashore. At the trough between the dunes, the sand layers are covered with a level of compact clays, with thickness up to $4 \mathrm{~m}$. The aquifer overlays marls from the Miocene, which are also the outcropping formations at the Oulad Mansour hills (Fig. 2). In the western limit of the plain, close to the Moulouya, the aquifer comprises alluvial deposits, alternating layers of gravelly and muddy terraces that are often fully saturated. This area, hereafter referred as the 'marshy area' (Fig. 1) receives inflow from the Triffa aquifer that lays to the south and which is known to have high-salinity values. Inflow from the Triffa aquifer occurs partly through two high-salinity springs, the Ain Zebda and the Ain Chebbak springs, along a tectonic structure-the Trouée (Boughriba et al. 2006).

There is shortage of information about the hydraulic parameters of the aquifer sands, but Melloul et al. (2006) indicate mean values of $7 \times 10^{-5} \mathrm{~m} / \mathrm{s}$ for the hydraulic conductivity of the coastal deposits, and $2 \times 10^{-4}$ to
Fig. 1 Location and geology of the study area. Oued Moulouya is a large river that bounds the aquifer; Oued Kiss is a seasonal river. Ain Chebbak and Ain Zebda springs are discharge points from the high-salinity Triffa aquifer, located to the South of the Oulad Mansour hills

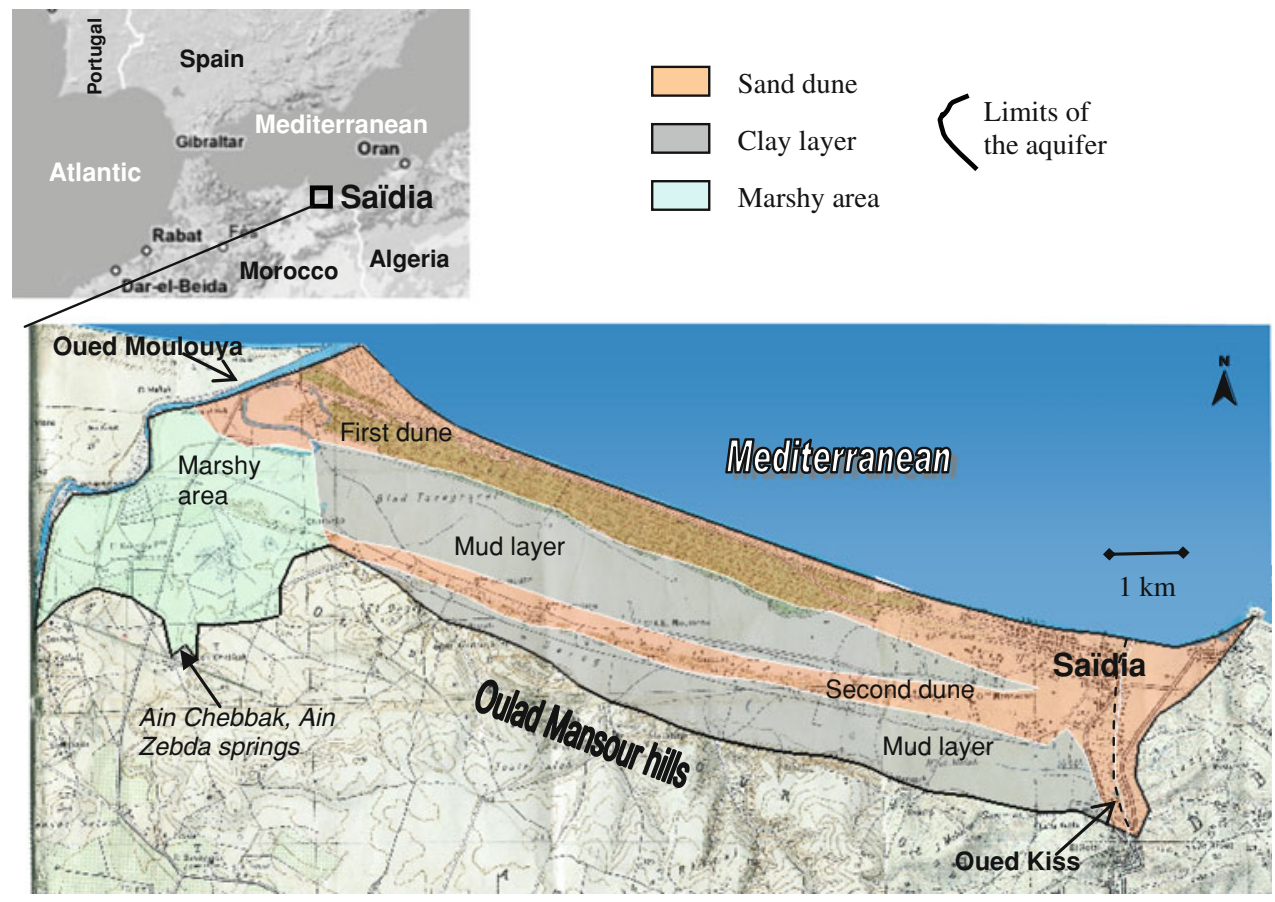




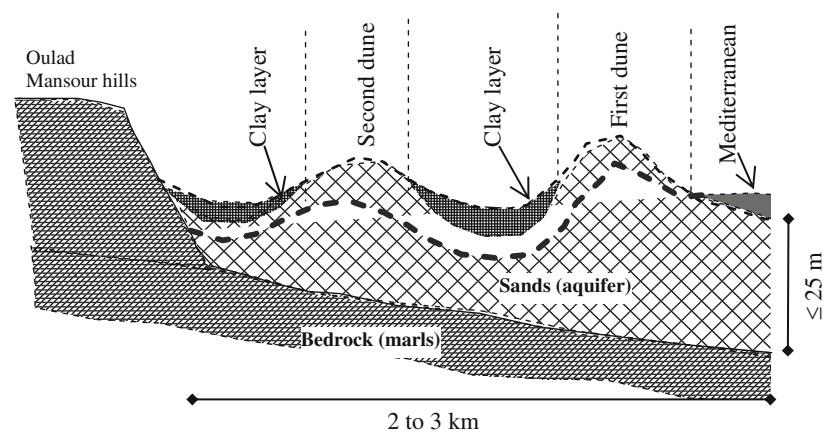

Fig. 2 Schematic geological cross sections. Not to scale. The marls outcropping at the Oulad Mansour hills and that underlay the aquifer are a source of salinity due to chemical reactions between groundwater and gypsum layers within the marls

$4 \times 10^{-5} \mathrm{~m} / \mathrm{s}$ for the marshy area. The coastal deposits are fairly uniform, but the marshy area shows considerable heterogeneity. Sandy deposits predominate in some zones of the marshy area which may explain why hydraulic conductivity can locally be above that in the coastal deposits.

Groundwater flow is generally from South to North, i.e., from the Oulad Mansour hills towards the Mediterranean, with the main exploitation wells, close to Oueds Moulouya and Kiss, generating a slightly depressed water table (Fig. 3). The well yields are typically small, on the order of a few litres per second. The hydraulic heads in the aquifer vary from a value of zero, at the seashore, to values of about $14 \mathrm{~m}$ at the Troueé, where inflow from the Triffa aquifer is significant (Fig. 3). The large perennial Oued Mouluoya is an influent source, but the role of the seasonal Oued Kiss is less clear, probably varying throughout the year. Recharge to the aquifer occurs mainly along the dunes, and was quantified by Melloul (2007) at about 23\% of the mean annual precipitation $(320 \mathrm{~mm})$.
Groundwater quality

Groundwater in Saïdia has a chemical composition dominated by sodium and chloride (Melloul 2007). Several sources of salinity contribute to the low quality of the groundwater (Melloul 2007; Melloul et al. 2006). Apart from the influence of the seawater, it is known that at the SW edge of aquifer, the Ain Zebda and Ain Chebbak springs discharge high-salinity groundwater into the Saïdia aquifer (Boughriba et al. 2006). The agricultural development of the lower Moulouya has also been responsible for the increased salinity of coastal groundwater aquifers, often leading to changes in agricultural practices or the abandonment of cultivated areas. Chetouani and Damou (1993) and Sadki (1996) have shown that salinity increases with depth and towards the Mediterranean, although high salinities were reported only at the seashore.

Table 1 presents the total dissolved solids (TDS), $\mathrm{pH}$ and electrical conductivity values in several of the piezometer in the area. The TDS values, which we will assimilate to total salinity, vary from minimum values of $553 \mathrm{mg} / \mathrm{l}$ up to $4,905 \mathrm{mg} / \mathrm{l}$, with a mean value of $2,820 \mathrm{mg} / \mathrm{l}$. Notice the high salinity of the groundwater discharging from the Ain Chebbak and Ain Zebda springs, with a mean value of $5,108 \mathrm{mg} / \mathrm{l}$.

\section{Numerical model}

The model was primarily designed as a tool to understand the sources of salinity in the aquifer and to be used for aquifer management purposes. A density-dependent numerical code, FEMWATER (Lin et al. 2001), was chosen to simulate density-dependent flow and transport in an aquifer where density gradients are known to be important.
Fig. 3 Hydraulic head distribution in the Saîdia aquifer (also shown the network of wells and piezometers). Contours built by kriging between hydraulic head values observed in the piezometer and imposing $h=0 \mathrm{~m}$ at the seashore

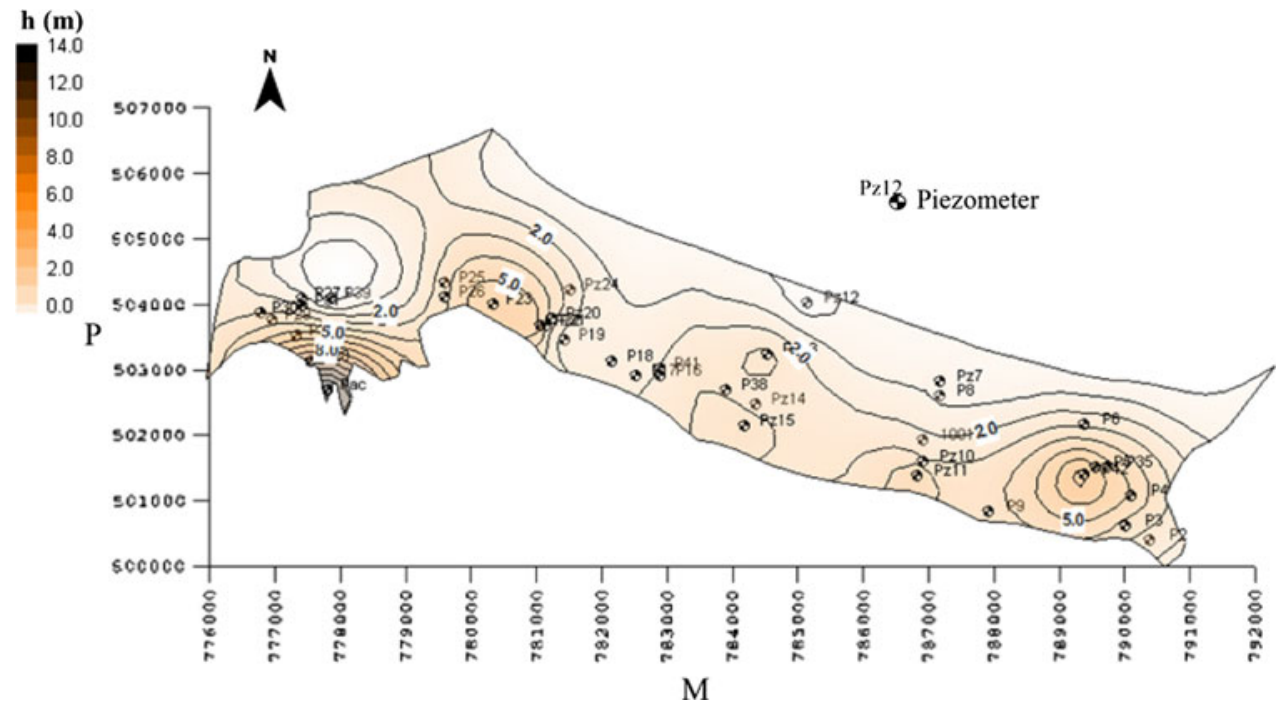


Table 1 Total dissolved solids ( $\mathrm{mg} / \mathrm{l}), \mathrm{pH}$ and electrical conductivity $(\mu \mathrm{S} / \mathrm{cm})$ reported by Melloul (2007)

\begin{tabular}{llll}
\hline Id. & TDS $(\mathrm{mg} / \mathrm{l})$ & $\mathrm{pH}$ & $\mathrm{EC}(\mu \mathrm{S} / \mathrm{cm})$ \\
\hline P1 & 3,720 & 7.72 & 5,150 \\
P2 & 3,641 & 7.68 & 4,970 \\
P4 & 3,355 & 7.68 & 4,970 \\
P5 & 4,041 & 7.65 & 5,650 \\
P6 & 1,064 & 8.42 & 1,220 \\
P7 & 3,047 & 8.05 & 4,040 \\
P9 & 4,905 & 7.9 & 6,780 \\
Pz10 & 1,875 & 8.35 & 2,770 \\
P16 & 553 & 8.2 & 437 \\
P18 & 2,553 & 8.09 & 3,390 \\
P22 & 3,545 & 8.13 & 5,890 \\
P23 & 1,859 & 8.02 & 2,790 \\
P26 & 2,135 & 8.29 & 3,333 \\
P27 & 3,264 & 7.96 & 4,450 \\
P33 & 2,755 & 7.83 & 3,870 \\
Ain Chebbak & 5,409 & 7.67 & 7,870 \\
Ain Zebda & 4,808 & 7.65 & 7,040 \\
Moulouya & 1,701 & 7.94 & 2,490 \\
\hline
\end{tabular}

The ability to model density-induced flow is relevant when assessing the climate changes impacts on coastal aquifers, since the main effects are likely to occur at the freshwater/ saltwater interface.

FEMWATER is a three-dimensional finite element groundwater model able to simulate flow and transport in both saturated and unsaturated zone. In FEMWATER flow and transport are coupled through the dependence of the density and dynamic viscosity on the salinity of the groundwater (Lin et al. 2001). A linear relationship of density $(\rho)$ and dynamic viscosity $(\mu)$ with salinity is assumed as:

$\frac{\rho}{\rho_{0}}=1+10^{-6} C, \quad \frac{\mu}{\mu_{0}}=1+10^{-6} C$

where $\rho_{0}$ and $\mu_{0}$ are the freshwater density and dynamic viscosity, respectively, and $C$ is the total salinity ( $\mathrm{mg} / \mathrm{l})$.

Modelling domain and boundary conditions

The modelling domain (Fig. 4a) was set to include all the coastal aquifer area, but the northern limit was extended up to $3 \mathrm{~km}$ into the Mediterranean Sea, so that a suitable constant concentration boundary could be imposed. The domain discretization considers 2,096 horizontal elements, with the mesh refined along the seashore and including five vertical layers to represent the density variation with depth. In total there are 10,480 active elements (Fig. 4a).
The Miocene bedrock and its outcrops in the Oulad Mansour hills were assigned impermeable boundary conditions. The Moulouya was set as a prescribed-head boundary, varying from $h=7 \mathrm{~m}$ at its upstream limit to $h=0 \mathrm{~m}$ at the Mediterranean. The southern limit of the marshy area was set as a constant flow boundary, with flux $q=0.043 \mathrm{~m} /$ day. Along the Mediterranean, a constant head boundary with $h=0 \mathrm{~m}$ was imposed. Direct recharge from precipitation was distributed along the dunes and in the marshy area, with a vertical constant flux $q=2 \times$ $10^{-4} \mathrm{~m} /$ day (Fig. 4b).

The transport boundary conditions were set as follows: the Mediterranean limit of the modelling domain was defined at a constant concentration of $39,400 \mathrm{mg} / \mathrm{l}$ (Bear et al. 1999). Notice that, unlike the flow boundary conditions, no transport condition was set to the upper layer of the model where it contacts with the Mediterranean, which permits the model to freely find the location of the freshwater/seawater interface. The Moulouya was set at a prescribed salinity varying from $2,000 \mathrm{mg} / \mathrm{l}$ upstream to $20,000 \mathrm{mg} / \mathrm{l}$ close to the Mediterranean. Along the southern boundary of the marshy area, a variable concentration was set similar to the mean salinity in the Ain Chebak and Ain Zebda springs, 5,100 mg/l. Where the aquifer is limited by the Miocene marls, which are regarded as sources of salinity, constant salinity values were adopted corresponding to the highest salinity value measured in the nearby wells. Finally, direct recharge was assigned a constant salinity of $165 \mathrm{mg} / \mathrm{l}$, resulting from $78 \%$ of evapotranspiration (Melloul 2007) of rainwater with initial salinity of $38 \mathrm{mg} / \mathrm{l}$ (Hem 1985).

The initial flow conditions were found by setting the initial hydraulic heads equivalent to the aquifer top and then run the flow model (no transport being considered) under steady state conditions. The resulting hydraulic heads were applied as the initial heads in the coupled flow and transport model. The initial concentration condition was set to coincide with an interpolated (kriged) map of concentrations measured in the field. The coupled flow and transport model was then run for a sufficient long time $\left(10^{5}\right.$ days) until a small change in heads and concentrations was obtained.

Calibration of the numerical model was done against water level and salinity measurements in 45 wells and piezometers presented by Melloul (2007). There was a single set of data, collected in the same season, so that the calibration is considered to represent equilibrium conditions.

Calibration was conducted simultaneously for heads and concentration, since these are coupled in density-dependent numerical models. A decision was made to compromise between simplicity of the model and the accuracy of the calibration. Owing to the scarcity of information on 
Fig. 4 Modelling domain and model discretization (a) and boundary conditions (b). The Mediterranean is assigned a constant head condition, but the concentration condition is set only to the northern limit of the model, so that model is able to freely find the freshwater/ saltwater interface

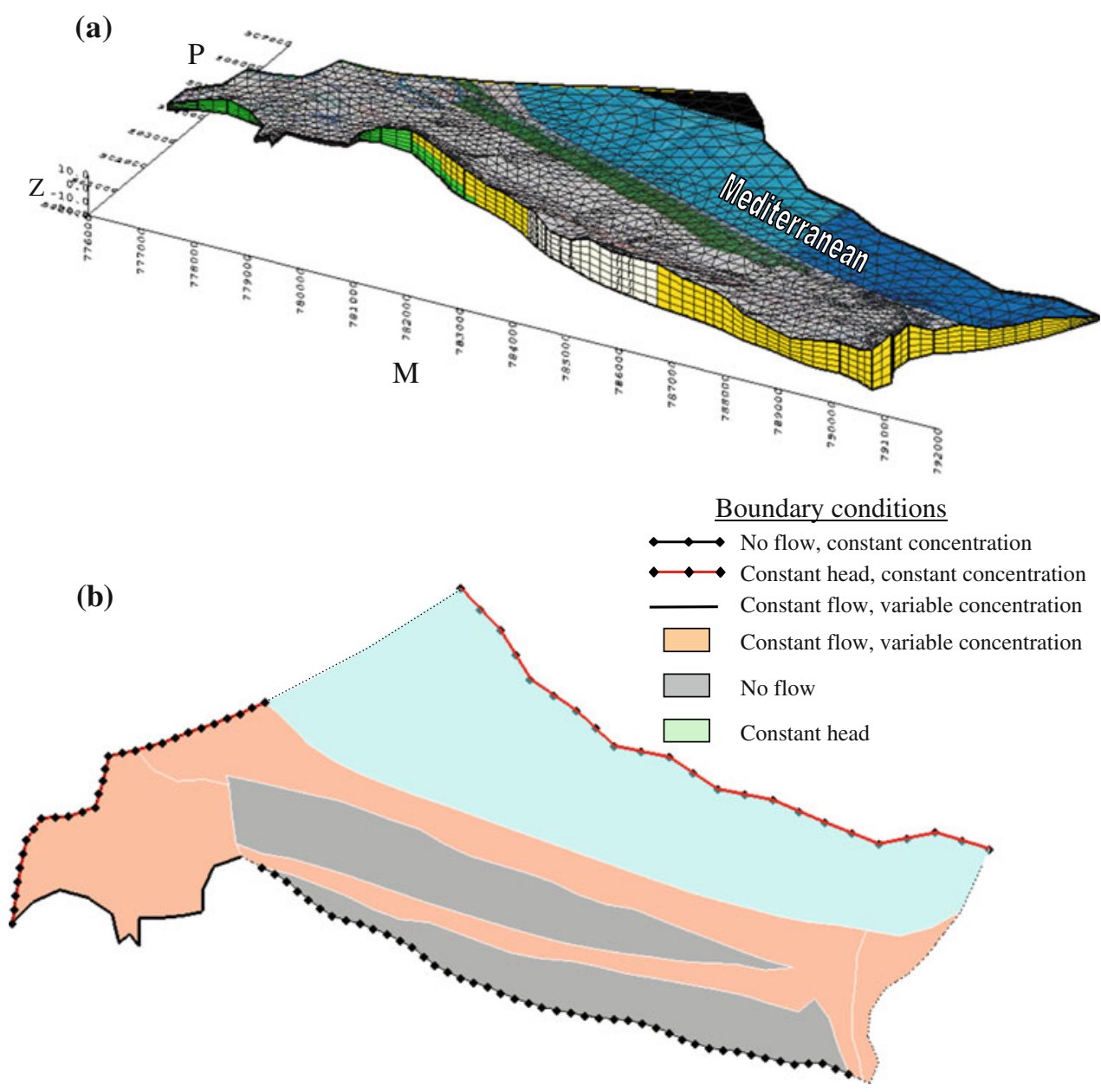

hydraulic parameters, it was considered artificial to force calibration by defining a large number of hydraulically different aquifer zones. Only three zones were considered: (1) a large zone encompassing most of the sandy aquifer; (2) a subset of the sandy aquifer, where it was necessary to adopt much smaller hydraulic conductivity values to achieve an acceptable calibration; and (3) the marshy area. The calibration parameters were the hydraulic conductivities and the flux and concentration assigned to the boundary conditions. Dispersivity was considered uniform, being $\alpha_{h}=10$ and in the vertical $\alpha_{v}=1$, so as to maintain approximately $\alpha_{h}=$ $d_{x} / 10$ where $d_{x}$ is the minimum length of the smaller model cells (about $100 \mathrm{~m}$ close to the seashore).

Figure 5 illustrates the calibration obtained for the unweighted hydraulic heads (Fig. 5a) and the unweighted salinities (Fig. 5b), which are considered acceptable, given the simplicity of the model and the lack of calibration data.

\section{Stresses related to IPCC scenarios}

The stresses imposed on the aquifer by climate changes were based on the scenarios put forward by the IV report of the Intergovernmental Panel on Climate Change (IPCC 2007), which provide estimates for the temperature, sea level rise, and precipitation changes up to 2,099.

Three IPCC scenarios were selected for analysis: (1) AlB scenario, the IPCC reference scenario; (2) B1 scenario, which shows the smallest variations in temperature and sea level rise; and (3) AlFI scenario, which is the worst-case scenario both in terms of sea level rise and temperature increase. These three scenarios were selected to encompass the whole range of changes in temperature, sea level and precipitation provided by the ensemble of the IPCC scenarios (Table 2).

The IPCC reference scenario (scenario A1B) predicts for the end of the twenty-first century a global sea level rise ranging from $21-48 \mathrm{~cm}$, a temperature increase from 1.7 to $4.4^{\circ} \mathrm{C}$ (Table 3), while in the Mediterranean it is expected a precipitation decrease from 4 to $27 \%$ (Table 4), with respect to the 1980-1999 mean values.

Global sea level rise and temperature variation for the two other scenarios are also provided in the IPCC reports, but values for precipitation variation in the west Mediterranean are not directly provided. Those were estimated according to: 

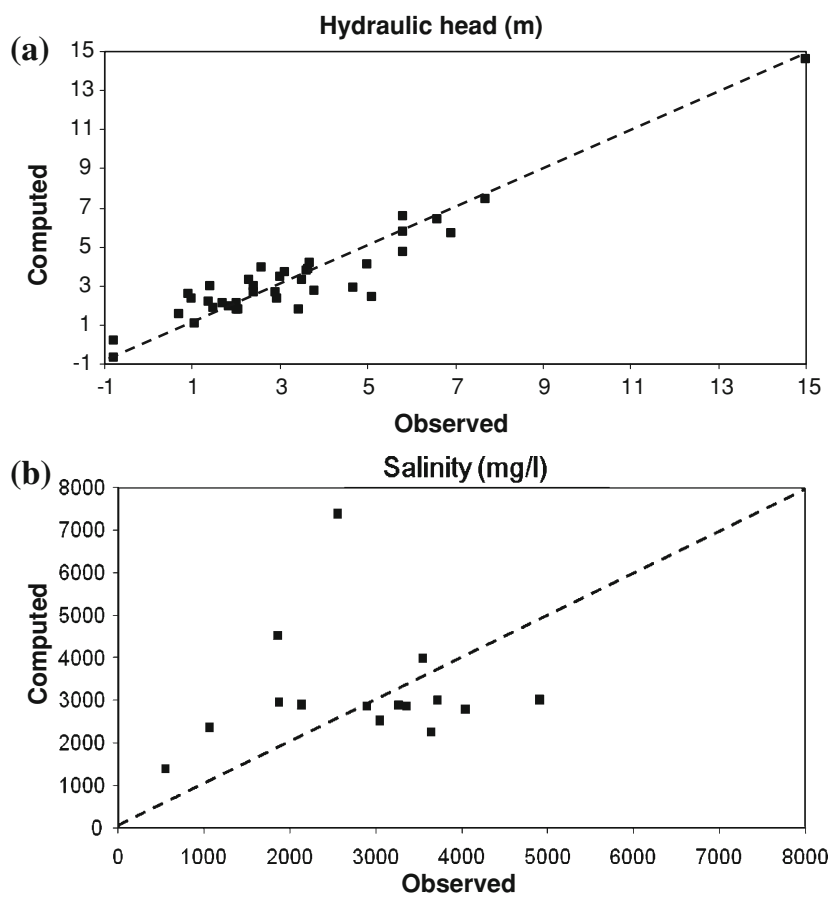

Fig. 5 Calibration plots: a observed and computed hydraulic heads, b observed and computed salinities. The dashed lines represent the perfect fit (1:1 line)

$$
\begin{aligned}
\Delta P_{B 1} & =0.69 \Delta P_{A 1 B} \\
\Delta P_{A 1 F I} & =1.42 \Delta P_{A 1 B}
\end{aligned}
$$

where $\Delta P$ is the precipitation variation, and 0.69 and 1.42 are the proportion between the responses of the scenario A1B, as given in Table 3 and the responses of the scenarios B1 and A1FI, respectively (IPCC 2007).

Table 4 lists the stresses imposed by climate change in the Saïdia area, although only two are included directly in the numerical model: (1) sea level rise - the effect of which is incorporated by changing the constant head value in the Mediterranean boundary of the model and in the top layer
Table 3 Temperature and precipitation response in the south Europe/ Mediterranean (SEM) zone for IPCC scenario A1B (adapted from

\begin{tabular}{|c|c|c|c|c|c|}
\hline \multirow[t]{2}{*}{ Region } & \multirow[t]{2}{*}{ Season } & \multicolumn{2}{|c|}{$\begin{array}{l}\text { Temperature } \\
\text { response }\left({ }^{\circ} \mathrm{C}\right)\end{array}$} & \multicolumn{2}{|c|}{$\begin{array}{l}\text { Precipitation } \\
\text { response }(\%)\end{array}$} \\
\hline & & Range & Mean & Range & Mean \\
\hline \multirow{5}{*}{$\begin{array}{l}\text { SEM } 30 N \text { to } 48 N \text {, } \\
10 \mathrm{~W} \text { to } 40 \mathrm{E}\end{array}$} & DJF & $1.7-4.6$ & 2.6 & -16 to +6 & -6 \\
\hline & MAM & $2.0-4.5$ & 3.2 & -24 to -2 & -16 \\
\hline & JJA & $2.7-6.5$ & 4.1 & -53 to -3 & -24 \\
\hline & SON & $2.3-5.2$ & 3.3 & -29 to -2 & -12 \\
\hline & Annual & $2.2-5.1$ & 3.5 & -27 to -4 & -12 \\
\hline
\end{tabular}
IPCC 2007)

of the model that is within the Mediterranean, and; (2) recharge decrease, resulting from the expected changes in temperature and precipitation, and which is incorporated into the numerical model as changes in the recharge to the sand dunes and in the inflow from the adjacent Triffa aquifer.

Estimate of recharge variation

Temperature and precipitation are not included directly in the numerical model, but they obviously affect the recharge rate. Melloul (2007) estimated the present-day recharge as $23 \%$ of the mean precipitation assuming that run off was negligible in the plain, so that:

$R=P-\mathrm{ETR}$

where $R$ is recharge, $P$ is precipitation and ETR is real evapotranspiration. To assess the variation in the recharge rate, it is necessary to know the variation in precipitation (which is provided by the IPCC reports), and in real evapotranspiration.

The variation in real evapotranspiration, as a function of temperature and precipitation was estimated using Turc's formula (1951):

\begin{tabular}{|c|c|c|c|}
\hline \multirow[t]{2}{*}{ Case } & \multicolumn{2}{|c|}{ Temperature change $\left({ }^{\circ} \mathrm{C}\right.$ at $2090-2099$ relative to $\left.1990-1999\right)$} & \multirow{2}{*}{$\begin{array}{l}\text { Sea level rise (m at } 2090-2099 \\
\text { relative to } 1990-1999) \\
\text { Model-based range excluding future } \\
\text { rapid dynamical changes in ice flow }\end{array}$} \\
\hline & Best estimate & Likely range & \\
\hline $\begin{array}{l}\text { Constant year } 2000 \\
\text { concentrations }\end{array}$ & 0.6 & $0.3-0.9$ & Not available \\
\hline B1 scenario & 1.8 & $1.1-2.9$ & $0.18-0.38$ \\
\hline A1T scenario & 2.4 & $1.4-3.8$ & $0.20-0.45$ \\
\hline B2 scenario & 2.4 & $1.4-3.8$ & $0.20-0.43$ \\
\hline A1B scenario & 2.8 & $1.7-4.4$ & $0.21-0.48$ \\
\hline A2 scenario & 3.4 & $2.0-5.4$ & $0.23-0.51$ \\
\hline A1FI scenario & 4.0 & $2.4-6.4$ & $0.26-0.59$ \\
\hline
\end{tabular}

Table 2 Temperature change and sea level rise for several IPCC scenarios (after IPCC 2007) 
Table 4 Stresses induced by climate change and included in the numerical model simulations

\begin{tabular}{lllllc}
\hline IPPC scenario & $\begin{array}{l}\text { Temperature } \\
\text { change }\left({ }^{\circ} \mathrm{C}\right)\end{array}$ & $\begin{array}{l}\text { Sea level } \\
\text { rise }(\mathrm{m})\end{array}$ & $\begin{array}{l}\text { Precipitation } \\
\text { decrease }(\%)\end{array}$ & $\begin{array}{l}\text { Recharge } \\
\text { decrease }(\%)\end{array}$ & Observations \\
\hline B1 & 1.1 & 0.18 & 6 & 9 & B1 lower values \\
A1B & 2.8 & 0.35 & 12 & 19 & A1B mean values \\
A1FI & 6.4 & 0.59 & 38 & 47 & A1FI higher values \\
\hline
\end{tabular}

$$
\mathrm{ETR}=-P\left[0.9+P^{2}\left(300+25 T+0.05 T^{3}\right)^{-2}\right]^{-1 / 2}
$$

The application of the temperature and precipitation variation into Eqs. 4 and 3 makes it possible to compute the recharge variation with respect to the present-day recharge. This analysis results in a recharge rate decreasing from $9 \%$ for the best-case scenario (B1), to $47 \%$ for the worst-case scenario (A1FI) of the present-day recharge (Table 4).

\section{Results of simulations}

The simulations were run according to the following procedure:

1. a quasi-steadystate situation, aimed at representing the existing conditions, was found by running the model for a very long time so that no relevant changes exist in hydraulic heads and salinity. The model was run for about $10^{5}$ days, with time steps increasing from 1 to 500 days. It was considered that the model had stabilized for a hydraulic head change $<1 \mathrm{~mm}$ and a salinity change $<1 \mathrm{mg} / \mathrm{l}$, for a time step of 500 days;

2. boundary conditions were changed so as to represent the recharge and sea level rise according to Table 4 . The Mediterranean boundary was set to vary linearly so that at 2099 the sea level rise would be equivalent to the values in Table 4. Recharge and inflow from the Triffa aquifer into the marshy area was also made to vary linearly to maximum values in 2099;

3 . having set this new boundary conditions the numerical model was run up to 2099;

4. the climate change influence was found from the difference between the hydraulic head and salinity solutions found in steps 1 and 3 .

Effect on the hydraulic heads and flow velocities

Figure 6 shows the hydraulic head differences due to climate change for the three IPCC scenarios under consideration. In every case, it is shown that the effect of increase in water levels implied by the sea level rise is counterbalanced by the decrease in recharge to the aquifer. Consequently, the water table rises only in the areas closer to sea shore, with the maximum increase being governed by the sea level rise, while in the areas closer to the Oulad Mansour hills the water table declines. Although in scenarios B1 (Fig. 6a) and A1B (Fig. 6b) neither the rises in water table nor the declines seem very important, ranging from -0.3 to $+0.3 \mathrm{~m}$, scenario A1FI, the worst-case scenario, shows that by 2099 the decrease in hydraulic heads due to reduced recharge can reach maximum values of almost $0.9 \mathrm{~m}$ at the southern limit of the aquifer (Fig. 6c).

At the main pumping areas drawdown will increase by $0.7 \mathrm{~m}$ in the Moulouya pumping zone and by $0.3 \mathrm{~m}$ in the Kiss pumping zone, which is not a cause of concern.

There is a clear decrease in hydraulic gradients, with the aquifer flow velocities being even smaller than nowadays (Fig. 7). This decline in the velocities is linked to a decrease in the freshwater flowing volume. In certain areas, the groundwater discharge to the Mediterranean drops down to $50-60 \%$ of the present-day values. That is, the renewable freshwater resources decrease considerably.

\section{Effect on the groundwater salinity}

The influence of climate change on the salinity of the groundwater is illustrated in Fig. 8. Salinity will increase sharply only in a relatively narrow area closer to the shoreline. This salinization is due not only to the sea level rise, but also to the decrease in recharge to the aquifer and consequent reduced groundwater discharge towards the Mediterranean. It is this latter factor that explains the large salinity increase in the worst-case scenario, A1FI, which can increase as much as 30,000 mg/l (Fig. 8c), when compared with the other scenarios (Fig. 8a, b), where salinity increase stays below 5,000 mg/l. In any case, the changes in salinity occur in a relatively narrow area and probably have a small relevance.

Figure 8 shows a further interesting feature. Close to the upstream Moulouya River, it is expected that salinity will decrease, due to added contribution of leakage from the river to the aquifer and diminished high-salinity discharge from the Triffa aquifer. The induced freshwater recharge from the low-salinity Moulouya River results in an 
Fig. 6 Variation in hydraulic head in 2099 , relative to present-day situation, imposed by the IPCC scenarios: a scenario B1, b scenario A1B and $\mathbf{c}$ scenario A1FI

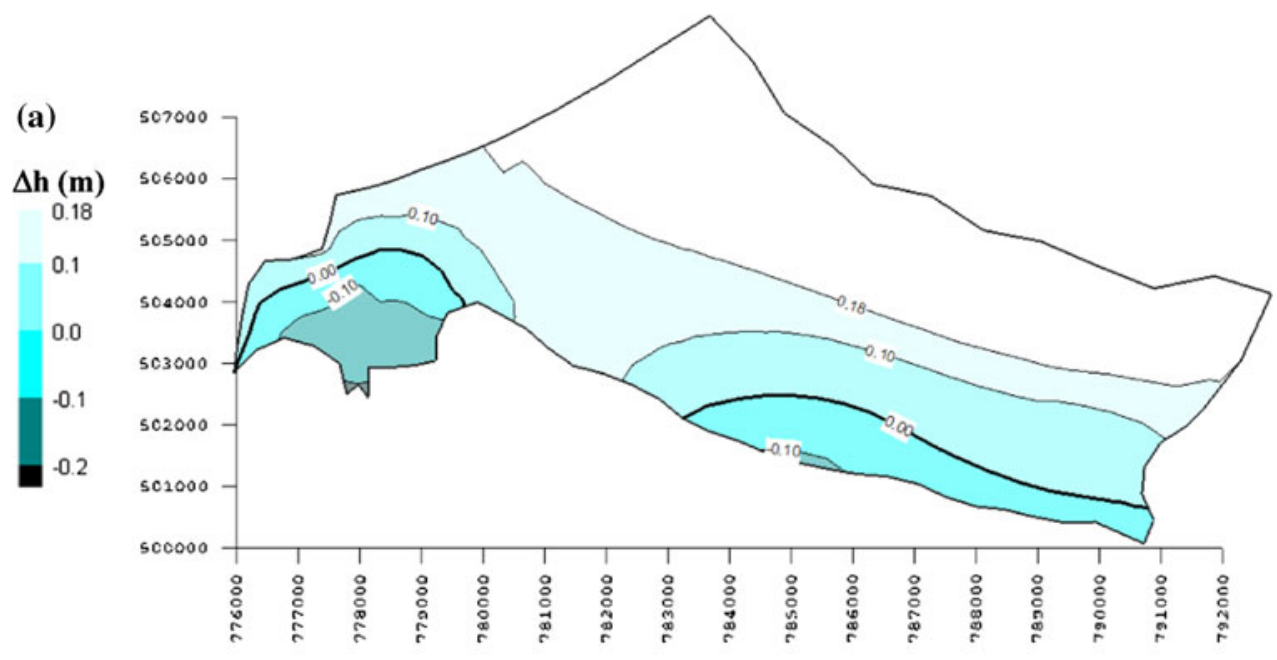

(b)
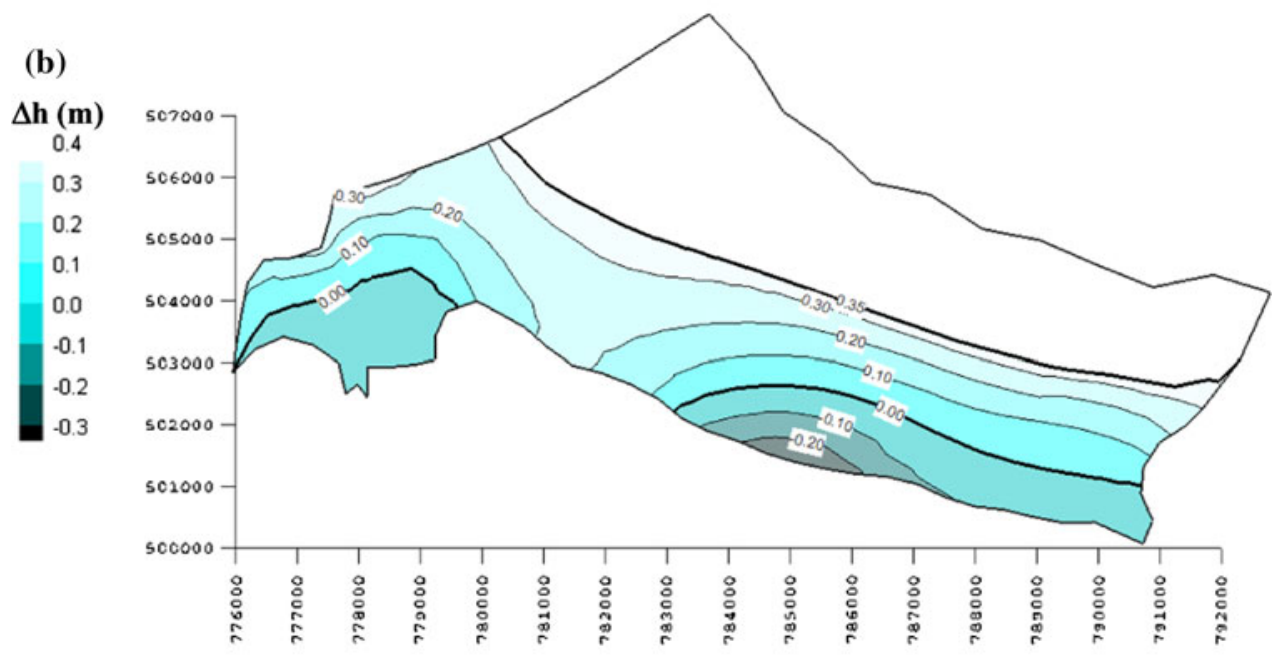

(c)

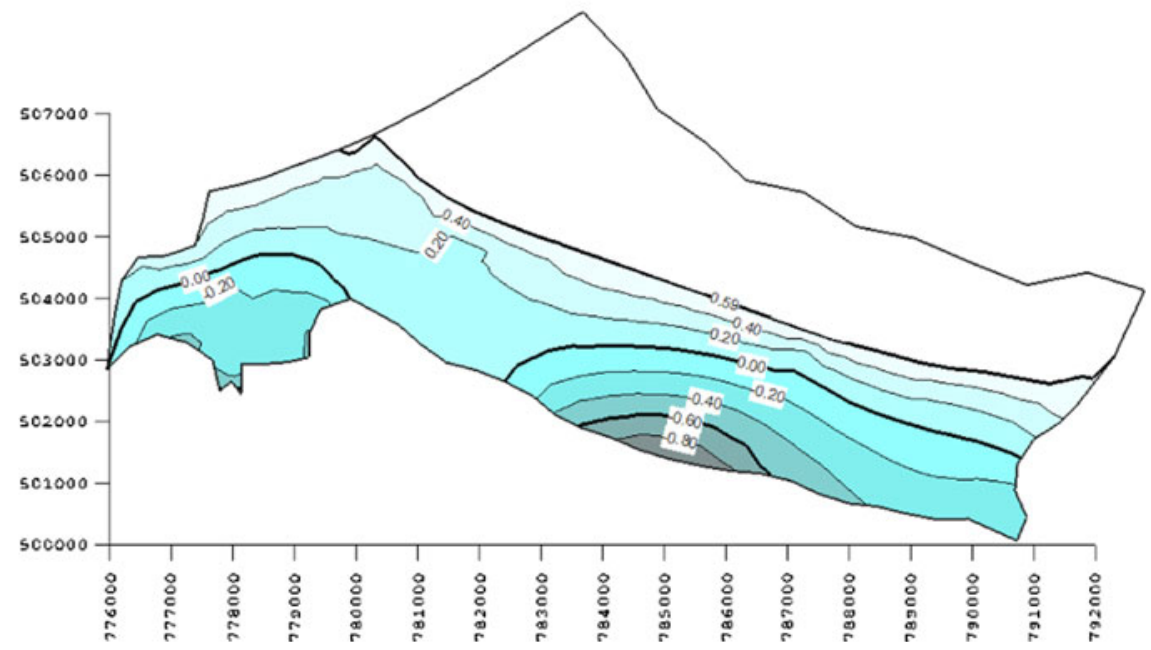

improvement of the groundwater chemical features, with salinity decreasing as much as $500 \mathrm{mg} / \mathrm{l}$ in the A1FI scenario.

This behaviour can be envisaged by the expected evolution of salinity in piezometer Pz39 (Fig. 9), close to the Moulouya (see Fig. 3), which shows a trend of decreasing in the total salinity for the A1FI scenario. Figure 9 also shows the salinity evolution in a piezometer located close to the present-day seashore, piezometer Pz12. Not surprisingly, due to the influence of sea level 
Fig. 7 Flow velocity imposed by: a present-day conditions, b imposed by A1FI scenario in 2099 (a)
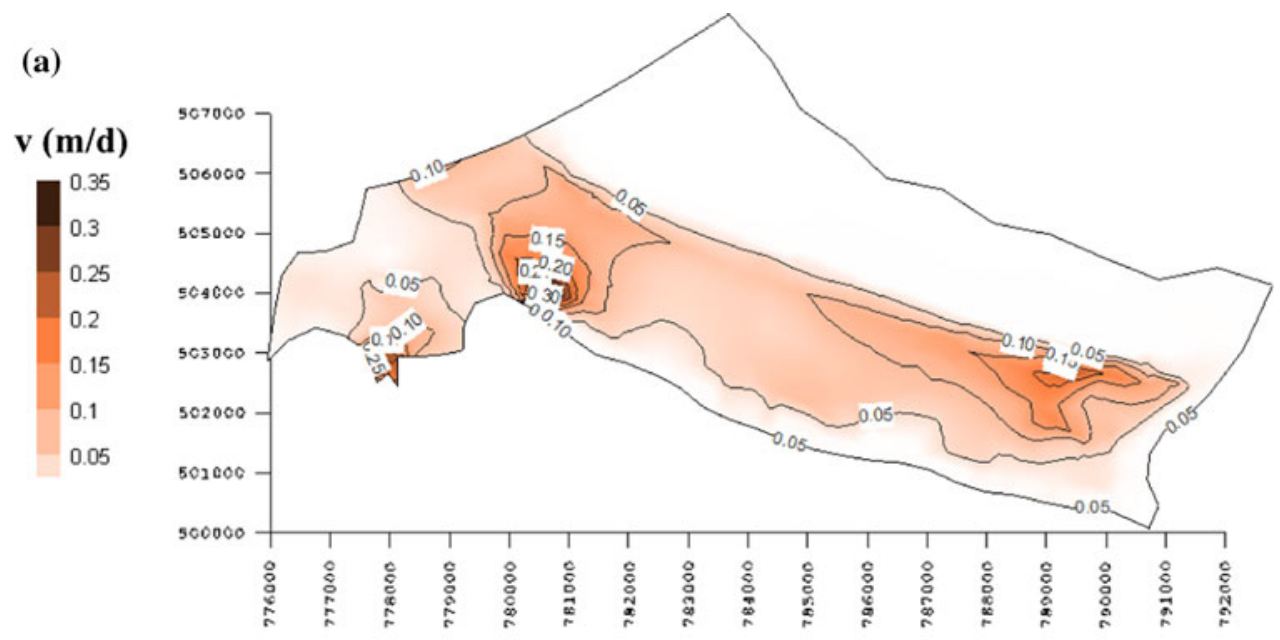

(b)

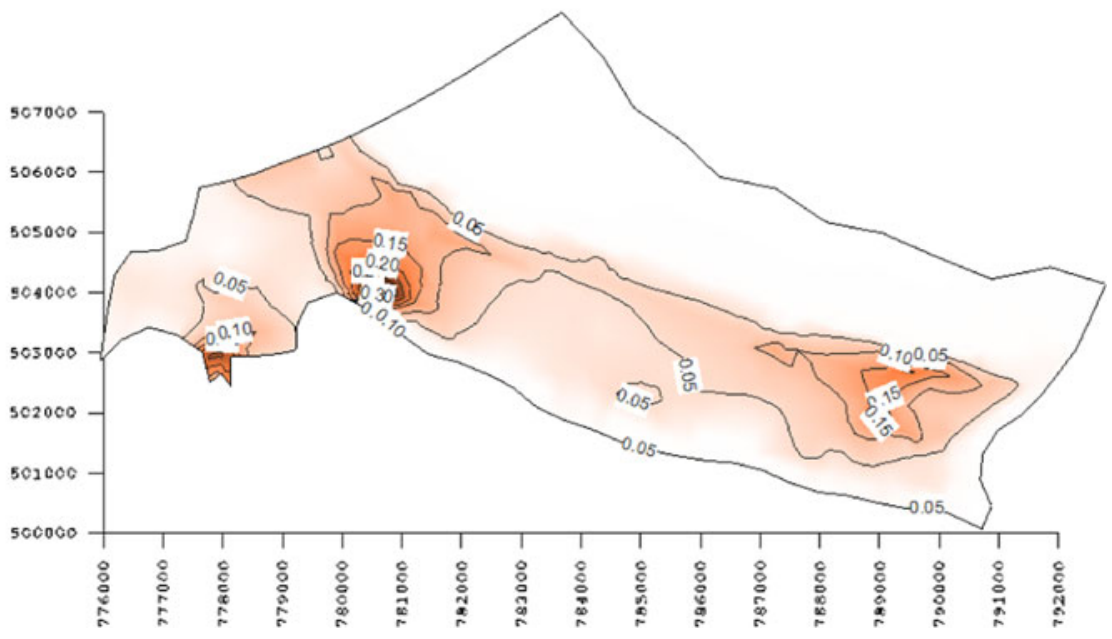

rise and reduced submarine discharge, salinity in piezometer P12 is expected to rise as much as 3,000 mg/l. However, this is only significant for the worst-case scenario, A1FI, with the other scenarios imposing much smaller salinity increases.

Nevertheless, the scaling down in flow velocity, and consequent contact time between groundwater and easily dissolved rocks can have several implications for the development of the area. It is likely that water quality in the low flow velocity zone will further decrease due to a higher accumulation of the dissolved salts, with obvious effects on groundwater usage. Existing buildings and underground infrastructures, designed for the existing groundwater salinity values, may also suffer consequences (such as corrosion) due to an increase in salinity.

It is important to mention that although the simulations cover the period until 2099, in agreement with the IPCC scenarios, that does not mean that the effect of the climate change on the groundwater conditions would not be felt afterwards, even if climate change was controlled and no further changes in climate were expected from 2099. Groundwater flow imposed by density gradients is a slow process in which hydraulic heads and concentrations evolve simultaneously, within time-scales that can last much longer than the original stresses (e.g., Darling et al. 1997; Edmunds and Milne 2001; Post 2005). Because solute transport in groundwater is generally a slow process, it is likely that present-day climate change effects will impose changes in the groundwater conditions that will extend for centuries, even if climate change is managed to be controlled within the next decades.

\section{Conclusions}

The use of numerical models as predictive tools, especially for long time periods as those in this study, by no means provides definitive answers, neither should be seen as tools that undoubtedly will forecast the response of the aquifer to a given management strategy. Even if models are perfectly calibrated and based on the sound field data, its application as predictive tools for very long time periods is questionable. The simulations presented in this paper aim to find the overall trends in declining or ascending heads, salinity and 
Fig. 8 Difference in total dissolved solids between the present-day situation and the situation in 2099 imposed by the IPCC scenarios. a B1 scenario, b A1B scenario and c A1FI scenario (a)

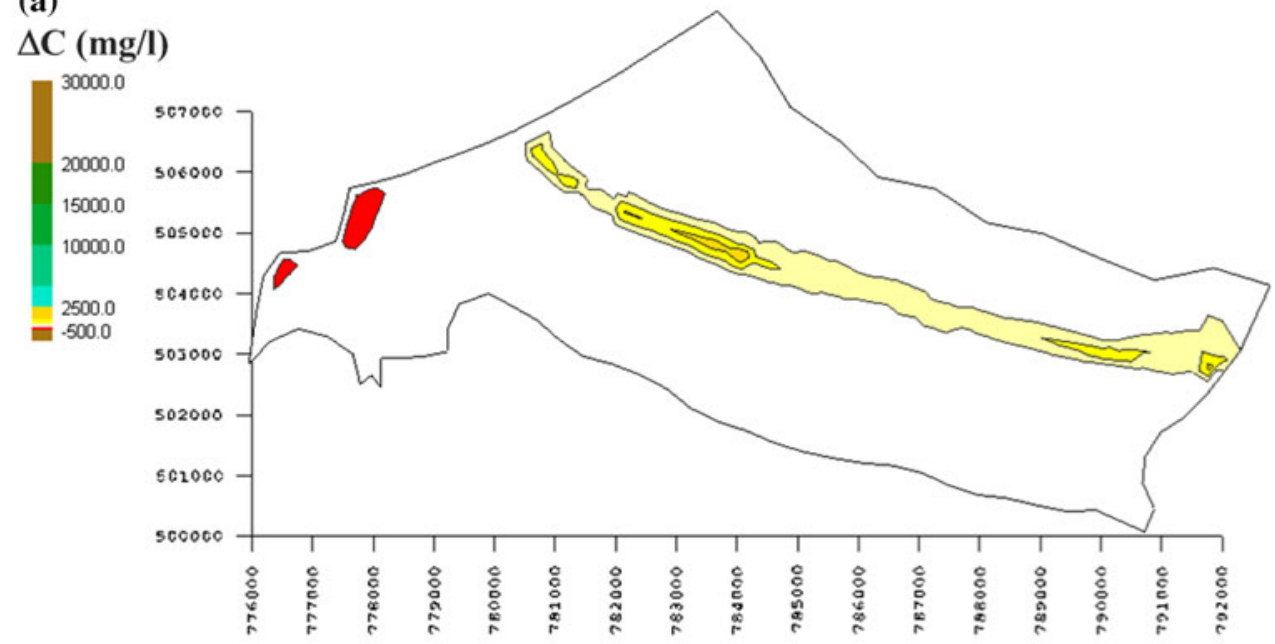

(b)

$\Delta \mathrm{C}(\mathrm{mg} / \mathrm{l})$

30000.0
20000.0
15000.0
10000.0
2500.0
.500 .0

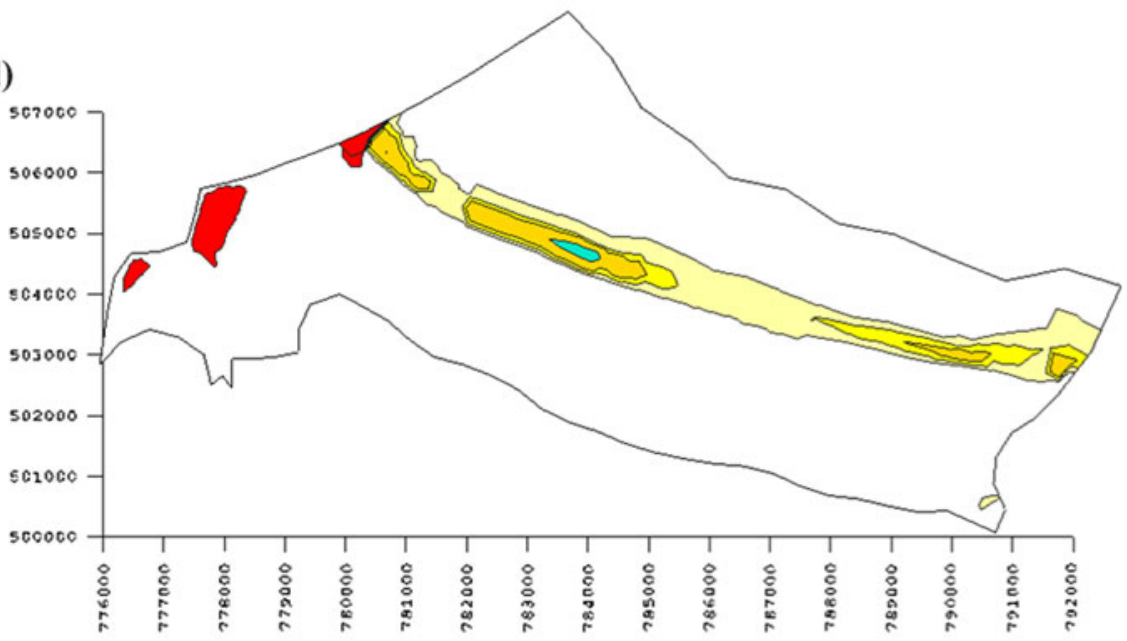

(c)

$\Delta \mathrm{C}(\mathrm{mg} / \mathrm{l})$

30000.0
20000.
15000.
10000.0
2500.0
-500.0

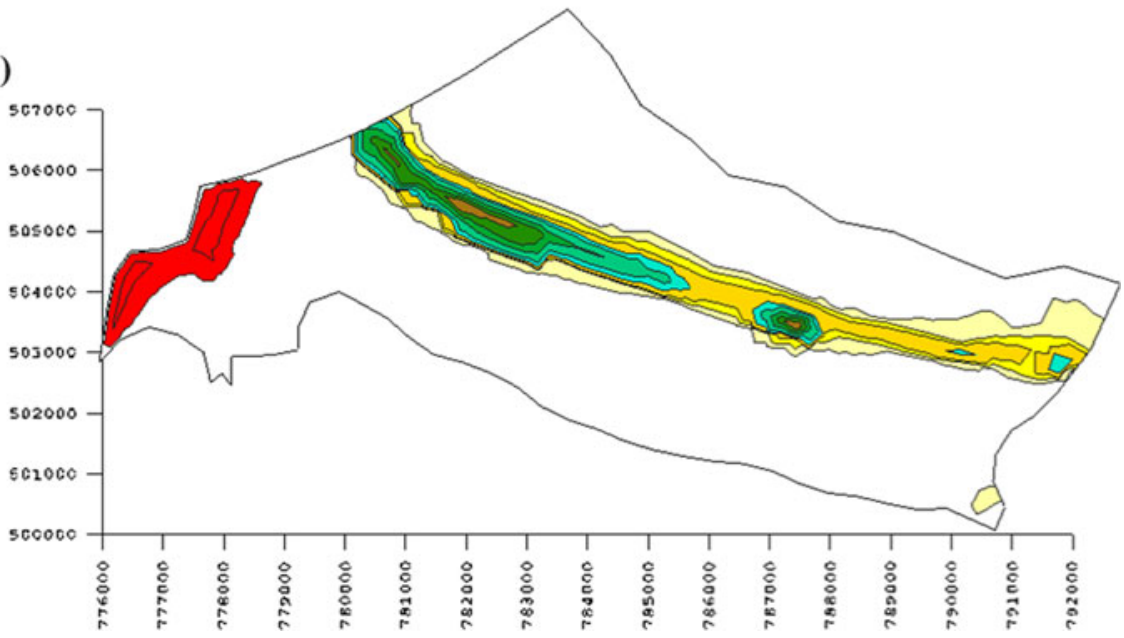

resources as a general view on the consequences of climate change to shallow coastal aquifers. In that respect, the conclusions of this study are likely to be of relevance for similar areas in the West Mediterranean.
The Saïdia shallow aquifer in NE Morocco shows characteristic high salinity, due to chemical reactions between the groundwater and the marls that bound the aquifer and due to passive seawater intrusion along the 

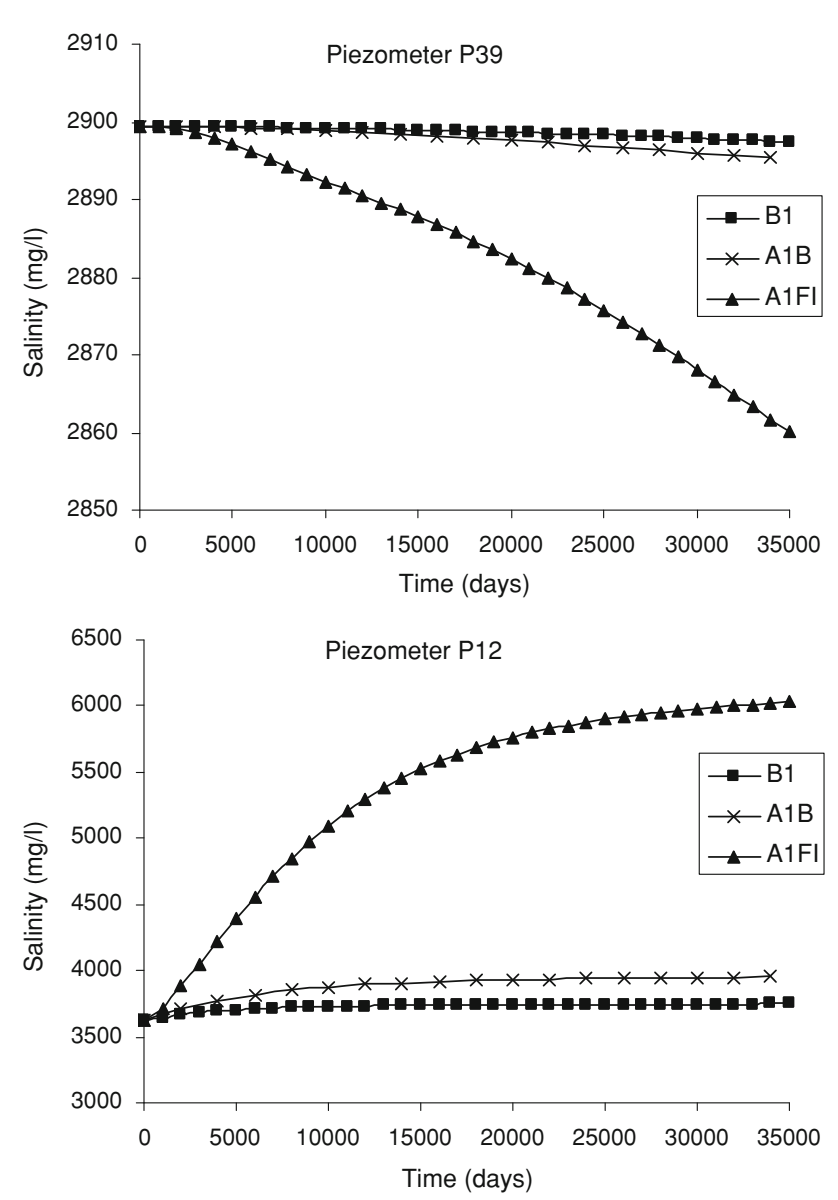

Fig. 9 Salinity evolution in piezometer P12, close to seashore, and piezometer P39, close to the Moulouya (see Fig. 3 for piezometer location), from present-day situation to 2099, for the several IPCC scenarios studied

Mediterranean coast. The area is currently undergoing fast touristic development, with considerable changes in land use and in the anthropogenic activities that affect the aquifer. A further cause of stress to the aquifer is climate change, potentially affecting aquifer recharge, and imposing sea level rise.

A numerical model was used to assess the influence of climate change, according to three IPCC scenarios, in the water levels and salinity in the aquifer. The regional predictions for the IPCC scenarios B1, A1B and A1FI were used, with the stresses imposed by climate change being the sea level rise and changes in the recharge rate, the latter being determined taking into consideration the expected variations in precipitation and in temperature.

The simulations period spans from present-day conditions to 2099. The simulations show that the main effect of climate change to the Saïdia aquifer will be a decrease in renewable resources, which may be reduced to $50-60 \%$ of present-day values, due to the decline in recharge and the diminished contributions from the adjacent Triffa aquifer.
This decrease in flow volume, reflected in declining water table at the upstream boundaries and rising water table close to the submarine discharge, will impose considerable changes in flow velocity and in the drainage of the upstream areas of the aquifer. In fact, some upstream areas will become almost stagnant and will tend to show an increased accumulation of the dissolved salts, due to the low flow velocities.

According to the simulations, the decreases in hydraulic heads will not be substantial, reaching maximum values around $0.9 \mathrm{~m}$ at the southern limit of the aquifer. At the main pumping area close to the Moulouya River, drawdown will increase by $0.7 \mathrm{~m}$, which is not significant. The areas close to the Mediterranean will be influenced mostly by sea level rise and will show a slightly ascending water table.

Similar conclusions can be drawn for the groundwater quality, with salinity increases being restricted to areas close to the seashore, at the seawater/freshwater interface, where salinity increase may ascend by as much as $30,000 \mathrm{~g} / \mathrm{l}$ in the A1FI scenario. However that increase occurs in a relatively narrow area and, therefore, is not too relevant. Interestingly, localised areas may see a small decrease in salinity due to the induced infiltration from the Moulouya River and diminished inflow from high-salinity springs.

Acknowledgments This study was partially funded by a joint grant from FCT-the Portuguese Foundation for Science and Technology - and from CNRST - the Moroccan National Centre for Scientific and Technology Research, CNRST-GRICESSDT/09.

\section{References}

Bates BC, Kundzewicz ZW, Wu S, Palutikof JP (2008) Climate change and water. In: IPCC (ed) Technical Paper of the Intergovernmental Panel on Climate Change. Geneva, pp 210

Bear J, Cheng A, Sorek S, Ouazar D, Herrera I (1999) Seawater intrusion in coastal aquifers: concepts, methods, and practices, theory and applications of transport in porous media. Kluwer, Dordrecht, p xv, 625

Ben Kabbour B, Zouhri L, Mania J (2005) Overexploitation and continuous drought effects on groundwater yield and marine intrusion: considerations arising from the modelling of Mamora coastal aquifer. Morocco Hydrol Process 19:3763

Boughriba M, Melloul A, Zarhloule Y, Ouardi A (2006) Spatial extension of salinization in groundwater and conceptual model of the brackish springs in the Triffa plain (northeastern Morocco). Cr Geosci 338:768-774

Carneiro JF, Boughriba M, Correia A, Zarhloule Y, Rimi A, Houadi BE (2008) Climate change impact in a shallow coastal Mediterranean aquifer, at Saïdia, Morocco. In: Langevin C, Lebbe L, Bakker M, Voss C (eds) 20th Salt water intrusion meeting, Naples, pp 30-33

Chetouani B, Damou S (1993) Diagnostic des problèmes d'engorgement des sols, de drainage et la qualité des eaux et des sols dans la plaine de Saïdia (Basse Moulouya). Thèse de 3ème cycle en Agronomie, Université de Rabat 
Cudennec C, Leduc C, Koutsoyiannis D (2007) Dryland hydrology in Mediterranean regions: a review. Hydrolog Sci J 52:1077-1087

Danielopol DL, Griebler C, Gunatilaka A, Notenboom J (2003) Present state and future prospects for groundwater ecosystems. Environ Conserv 30:104-130

Darling WG, Edmunds WM, Smedley PL (1997) Isotopic evidence for palaeowaters in the British isles. Appl Geochem 12:813-829

Edmunds WM, Milne CJ (2001) Palaeowaters in coastal Europe: evolution of groundwater since the late Pleistocene. Geological Society Publishing House, Bath

Hem JD (1985) Study and interpretation of the chemical characteristics of natural water, 3rd edn. Department of the Interior, USGS, Alexandria, VA

Holman IP (2006) Climate change impacts on groundwater rechargeuncertainty, shortcomings, and the way forward? Hydrogeol $\mathbf{J}$ $14: 637-647$

IPCC (2007) Climate change 2007: impacts, adaptation and vulnerability. Contribution of working group II to the fourth assessment report of the intergovernmental panel on climate change. Cambridge University Press, Cambridge, UK, pp 976

Lin H, Richards D, Talbot C, Yeh G, Cheng J, Cheng H, Jones N (2001) FEMWATER: a three-dimensional finite element computer model for simulating density-dependent flow and transport in variably saturated media, Version 3.0 users manual. U.S. Army Engineer Waterways Experiment Station, pp 151

Melloul A (2007) Etude d'impacts naturels et anthropiques sur l'évolution de la minéralisation de la nappe côtière de Saïdia par le biais d'une approche multidisciplinaire, couplée à un essai de modélisation et une cartographie de la vulnérabilité environnementale. $\mathrm{PhD}$, Université Mohammed Premier, Oujda

Melloul A, Boughriba M, Zarhloule Y, Probst JL, Boufiada M, El Mandour A, Snoussi M (2006) Vulnerability assessment of groundwater resources: evaluation of seawater intrusion and effect of climatic change. Coastal plain of Saïdia Morocco. Publicaciones del Instituto Geologico y minero de España Serie: Hidrogeología y Aguas Subterráneas 17:195-199

Moustadraf J, Razack M, Sinan M (2008) Evaluation of the impacts of climate changes on the coastal Chaouia aquifer, Morocco, using numerical modeling. Hydrogeol J 16:1411-1426

Post VEA (2005) Fresh and saline groundwater interaction in coastal aquifers: is our technology ready for the problems ahead? Hydrogeol J 13:120-123

Sadki R (1996) Evolution spatiale et temporelle de la salinisation dans la nappe côtière de Saïdia. 3ème cycle Thése de 3ème cycle, Université Mohammed Premier

Sherif MM, Singh VP (1999) Effect of climate change on sea water intrusion in coastal aquifers. Hydrol Process 13:1277-1287

Turc L (1951) Nouvelle formule pour le calcul du bilan de l'eau en fonction des valeurs moyennes annuelles des precipitations et de la temperature. Comptes Rendus Hebdomadaires des Sciences de L'Academie des Sciences 233:633-635 